\title{
DEFLECTIONS AND FREQUENCIES OF NATURAL OSCILLATIONS OF SYSTEMS OF COMPOSITE TWO-LAYER ISOTROPIC PLATES OF THE ROUND SHAPE AT THE CHANGE OF THICKNESS OF ONE OF THE LAYERS
}

\author{
Andrey Viktorovich Turkov* \\ Southwest State State University, Kursk, Russia \\ Natalia Sergeyevna Abashina \\ Orel State University, Orel, Russia \\ Olga Anatolyevna Vetrova \\ Orel State University, Orel, Russia
}

The paper presents a study on the relationship of the maximum deflections and fre-quencies of the fundamental tone of transverse oscillations of a number of composite two-layer plates of a round shape, rigidly pinched and pivotally supported on the contour. In the course of work we determined the maximum deflectionWO from the action of the static load and the natural oscillation frequency $\omega$ of the composite plates. We defined the proportio-nality coefficient $K$. According to the results, we designed the graphs of the maximum def-lection change and the frequency of natural oscillations when changing the thickness of one layer of the composite plate.

Key words: Composite plate, Maximum deflection, Frequency of natural oscillations, Coefficient of plate proportionality

\section{INTRODUCTION}

The determination of static and dynamic characteristics reduces to determining the deflections and frequencies of oscillations of systems in solving appropriatedifferential equations. The functional connection between the maximum deflection and the fundamental tone frequency of natural transverse oscillations of elastic isotropic plates was proved by V.I. Korobko [02, 03].

The differential equation of the plate transverse deflection has the form:

$D\left(\frac{\partial^{4} W}{\partial x^{4}}+2 \frac{\partial^{4} W}{\partial x^{2} \partial y^{2}}+\frac{\partial^{4} W}{\partial y^{4}}\right)-q(x, y)=0$.

With the use of biharmonic operators, the equation takes the form:

$$
\mathrm{D} \Delta^{2} \Delta^{2} \mathrm{~W}-\mathrm{q}(\mathrm{x}, \mathrm{y})=0 \text {, }
$$

where $W=W(x, y)$ is the deflection function of the plate at the transverse deflection; $d 2 d 2$ is a biharmonic operator; $D=E H^{3} /\left(12\left(1-v^{2}\right)\right)$ is cylindrical stiffness of the plate; $q(x, y)$ is the law of the transverse load change. The differential equation of plate free oscillations:

$$
\begin{gathered}
D\left(\frac{\partial^{4} W}{\partial x^{4}}+2 \frac{\partial^{4} W}{\partial x^{2} \partial y^{2}}+\frac{\partial^{4} W}{\partial y^{4}}\right)+m \frac{\partial^{2} W}{\partial t^{2}}=0 \\
D \Delta^{2} \Delta^{2} W+m \frac{\partial^{2} W}{\partial t^{2}}=0
\end{gathered}
$$

where $\mathrm{W}=\mathrm{W}(\mathrm{x}, \mathrm{y}, \mathrm{t})$ is the deflection function of a freely oscillating plate; $m$ is the mass per unit area of the plate; E, are respectively the modulus of elasticity of the material and the Poisson's ratio.

If the oscillations are harmonic:

$\mathrm{W}=\mathrm{W}(\mathrm{x}, \mathrm{y}) \cos (\omega \mathrm{t})$,

then equation (2.1) can be transformed to the following form:

$\mathrm{D} \Delta^{2} \Delta^{2} \mathrm{~W}-\mathrm{m} \omega^{2} \mathrm{~W}=0$ 
or

$$
\mathrm{D} \Delta^{2} \Delta^{2} \mathrm{~W}-\beta^{2} \mathrm{~W}=0 \text {, }
$$

Let us represent the deflection function as a product of the maximum deflection WOby the unit function $f(x, y)$ and substitute it in the differential equations of transverse deflection and free oscillations of the plates:

$W(x, y)=W \_0 f(x, y) ;(2.6)$

It should be noted that the exact solution of these differential equations is valid only in the frequent cases of plate forms and boundary conditions, therefore, in practice, approximate methods of solution are mainly used.

If we assume that the plate is under a uniformly distributed load $\mathrm{q}$, then having integrated equations (2.6) over the entire area of the region, and having performed the necessary transformations, we get:

$$
W_{0}=\frac{q}{D} \frac{A}{\iint_{A} \Delta^{2} \Delta^{2} f d A}, \quad \omega^{2}=\frac{D}{m} \frac{\iint_{A} \Delta^{2} \Delta^{2} \mathrm{fd} A}{\iint_{A} f d A} .
$$

The deflection function $\mathrm{W}(\mathrm{x}, \mathrm{y})$ can approximately be put downin a one-parameter form in the polar coordinate system:

$W(x, y)=W_{0} f(x, y)=W_{0} g[t / r(\varphi)]=W_{0} g(\rho)$,

where $r=r(\varphi)$ is the equation of the contour of the plate in the polar coordinate system, $t$ and $\varphi$ are polar coordinates, $\rho=t / r(\varphi)$ is the dimensionless polar coordinate.

This function describes a surface which level lines are similar to the region contour and are similarly located. The representation of the function of deflections in this form is justified by the fact that through it we can write down the exact solution to the problem of transverse deflection of a rigidly pinched elliptical plate under the action of a uniformly distributed load.Since just in the only case it is possible to represent the real deflection function in the form of a one-parameter function (2.8), further results are of an approximate nature.

We transform the integrals in (2.7), taking into account the deflection function in form (2.8).

$$
\iint_{A} f d A=\int_{0}^{2 \pi} \int_{0}^{r} g(\rho) \operatorname{tdtd} \varphi .
$$

Multiplying and dividing the right-hand side by $r 2$, we get after the transformations:

$$
\iint_{A} f d A=2 A \int_{0}^{1} g(\rho) \rho d \rho .
$$

Completing the transformation of the integral of the biharmonic operator according to [84], we finally write:

$$
\mathrm{I} \approx\left(\mathrm{K}_{\mathrm{f}}^{2} \Phi_{\mathrm{g} 1}+\mathrm{K}_{\mathrm{f}} \Phi_{\mathrm{g} 2}\right) / 2=\mathrm{K}_{\mathrm{f}}\left(\mathrm{K}_{\mathrm{f}} \Phi_{\mathrm{g} 1}+\Phi_{\mathrm{g} 2}\right) / \mathrm{A} .
$$

where

$$
\begin{aligned}
& \Phi_{g 1}=\frac{1}{2} \int_{0}^{1}\left(g^{\prime v} \rho-12 g^{\prime \prime \prime}-21 g^{\prime \prime} \rho^{-1}-3 g^{\prime} \rho^{-2}\right) d \rho \\
& \Phi_{g 2}=\frac{\pi}{2} \int_{0}^{1}\left(2 g^{1 v} \rho+14 g^{\prime \prime \prime}+22 g^{\prime \prime} \rho^{-1}+3 g^{\prime} \rho^{-2}\right) d \rho
\end{aligned}
$$

The sign of the approximate equality in (2.11) appeared under the transformation of integrals by means of the Bunyakovsky inequality [05].

We substitute the integrals (2.9) and (2.11) into the expressions (2.6). After the necessary transformations, we get:

$$
\left\{\begin{array}{l}
W_{0} \approx \frac{q A^{2}}{D} \frac{1}{K_{f}^{2} \Phi_{g 1}+K_{f} \Phi_{g 2}}, \\
\omega^{2} \approx \frac{D}{2 A^{2} m} \frac{K_{f}^{2} \Phi_{g 1}+K_{f} \Phi_{g 2}}{\int_{0}^{1} g \rho d \rho}
\end{array}\right.
$$

Since all the values of the definite integrals occurring in the expressions (2.13) are constant numbers depending on the accuracy of the choice of function $g(f)$, they can be represented as the proportionality coefficients $\mathrm{Kw}, \mathrm{K \omega}$ and $\mathrm{B}$. Then

$$
W_{0}=K_{w} \frac{q}{D} \frac{A^{2}}{K_{f}^{2}+B K_{f}}, \quad \omega^{2}=K_{o} \frac{D}{m} \frac{K_{f}^{2}+B K_{f}}{A^{2}},
$$

where

$$
\mathrm{K}_{\mathrm{w}}=1 / \Phi_{g 1} ; \quad \mathrm{K}_{\omega}=\frac{1}{2} \Phi_{g 1} / \int_{0}^{1} \mathrm{g \rho d} \rho ; \quad \mathrm{B}=\Phi_{\mathrm{g} 2} / \Phi_{\mathrm{g} 1} .
$$

Strictly speaking, the signs of approximate equalities should be put in expressions (2.14), in view of (2.12) and the approximation of function $g(f)$. 
Let us multiply the expressions (2.14) to each other:

$$
\mathrm{W}_{0} \omega^{2}=\mathrm{K}_{\mathrm{w}} \mathrm{K}_{\omega} \frac{\mathrm{q}}{\mathrm{m}}=\mathrm{K} \frac{\mathrm{q}}{\mathrm{m}} \text {. }
$$

Taking into account that the coefficients $\mathrm{Kw}$ and $\mathrm{K} \omega$ depend on the shape of the plate, the following regularity can be obtained from the expression (2.15): for elastic isotropic plates of identical shapes with homogeneous boundary conditions, the product of the maximum deflection WO from the action of the uniformly distributed load q per square of their fundamental frequency of transverse oscillations in the unloaded state, $\omega 2$ with accuracy up to the dimensional factor $\mathrm{q} / \mathrm{m}$ is a constant.Thus, it is mathematically and rigorously proved that for the whole set of plates with homogeneous boundary conditions the product W0. $\omega 2$ will be represented by a single curve. An important feature of the formulated regularity is the fact that the product W0. $\omega 2$, which is considered in it, does not depend on the flexural rigidity and dimensions of constructions.

Forms of plates can be very diverse - from round to infinitely elongated. It is quite appropriate to expect that the boundary values of the curve $K=$ W0.w2 will correspond exactly to these plates.

A large number of works are devoted to the calculation of solid and composite plates $[1,13,15$, $16]$, but no research has been carried out so far on the relationship between the static and dynamic parameters of the construction. In [4-12], the dependence (2.15) was considered for composite plates.

\section{CALCULATION OF COMPOSITE PLATES}

The calculate construction is a round plate in diameter, $1 \mathrm{~m}$ in diameter, consisting of two layers. In the work, we calculate several plates, the bottom layer of each of which has a thickness of 10 $\mathrm{mm}$, and the upper layer is different: $10,11,12$, $13,14,15,16,17,18,19,20,30,50$ and 100 $\mathrm{mm}$. Plates with hinged support and rigid pinching along the contour are considered.

Each layer of the plate is divided into finite elements, obtained by dividing the surface of the plate by circles with a spacing of $100 \mathrm{~mm}$ - by 10 rings, and by rays from the center, which divide the plate into 40 sectors.

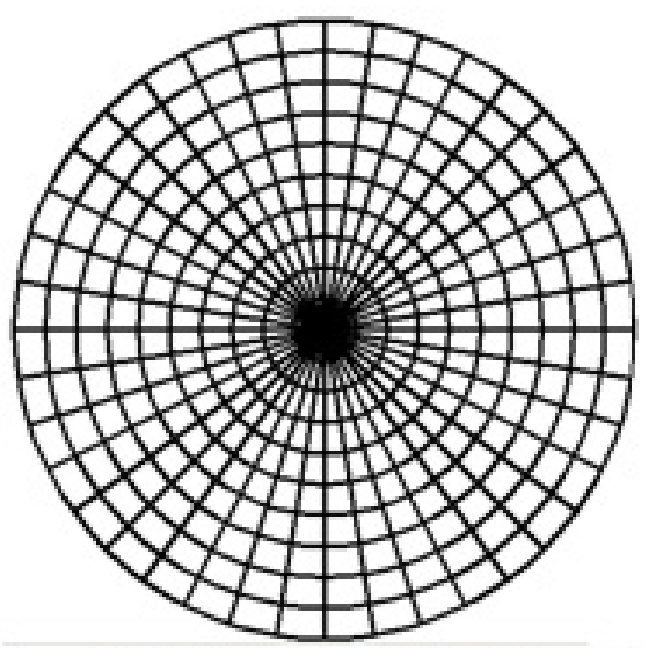

Figure 1: Calculation scheme of the plate

The rigidity of the transverse connections is constant, and it is EAc $=644 \mathrm{kH}$. All characteristics of the layers are taken for the chipboard plate: the average density is $\rho=720 \mathrm{~kg} / \mathrm{m} 3$, the elastic modulus at bending is $\mathrm{E}=2600 \mathrm{MPa}$. For dynamic calculation, the masses in the units were assembled in accordance with the volumetric weight and the load area of the unit, taking into account the thickness of the plate layer.With static calculation, a uniformly distributed load $q=$ $1 \mathrm{kH} / \mathrm{M} 2$ was applied to the upper layer. The studies were carried out by the finite element method. The distance between the layers was assumed to be equal to the distance between the centers of gravity of the layers.

Numerical studies were carried out with the help of the SCAD program [14]. In the course of the studies, the maximum deflection $\mathrm{W} O$ and the frequency of free transverse oscillations $\omega$ were determined. The results of calculating the plates are given in Table 1. According to Table 1, the graphs of the change in the maximum deflections and oscillation frequencies in the investigated plates and the proportionality coefficient $\mathrm{K}$ were built. The deviation of the actual value of the coefficient $\mathrm{K}$ from the theoretical value was determined by the formula:

$$
\Delta=\frac{\mathrm{K}_{\text {theor }}-\mathrm{K}}{\mathrm{K}_{\text {theor }}} 100 \%
$$


Table 1: Results of calculating plates with different thickness of layers

\begin{tabular}{|c|c|c|c|c|c|c|}
\hline $\begin{array}{c}\text { Thickness } \\
\text { of the up- } \\
\text { per layer } \\
h_{8}\end{array}$ & $\begin{array}{c}\text { Thickness } \\
\text { of the } \\
\text { lower } \\
\text { layer } \mathrm{h}_{4}\end{array}$ & $\begin{array}{c}\text { Maximum } \\
\text { deflection } W_{0} \\
\text { (мм) }\end{array}$ & $\begin{array}{c}\text { Frequency } \\
\text { ofnatural } \\
\text { oscillations } \omega \\
\left(\mathrm{c}^{-1}\right)\end{array}$ & $\mathrm{K}$ & $K_{\text {tneary }}$ & $\Delta(\%)$ \\
\hline \multicolumn{7}{|c|}{ Rigid pinching on the contour } \\
\hline$\overline{10}$ & $\overline{10}$ & 2.1746 & 227.672 & 1.668 & \multirow{14}{*}{1.629} & 2.35 \\
\hline$\overline{11}$ & $\overline{10}$ & 1.8658 & 239,8678 & 1.623 & & -0.36 \\
\hline 12 & 70 & 1.6088 & 253.7861 & 1.641 & & 0.75 \\
\hline$\overline{13}$ & $\overline{10}$ & 1.3604 & 268.4148 & 1.623 & & -0.36 \\
\hline 14 & 70 & 1.1617 & 284.3608 & 1.623 & & -0.36 \\
\hline$\overline{15}$ & $\overline{10}$ & 0.9941 & 301.1926 & 1.623 & & -0.35 \\
\hline 16 & 10 & 0.8535 & 318.7338 & 1.623 & & -0.36 \\
\hline$\overline{17}$ & $\overline{10}$ & 0.7355 & 336.9048 & 1.623 & & $-0,38$ \\
\hline 18 & 10 & 0.6366 & 355.6283 & 1.623 & & -0.36 \\
\hline$\overline{19}$ & 10 & 0.5534 & 374.7942 & 1.623 & & -0.36 \\
\hline 20 & 10 & 0.4832 & 394.3462 & 1.624 & & -0.37 \\
\hline 30 & $\overline{10}$ & 0.1553 & 602.3789 & 1.622 & & -0.37 \\
\hline$\overline{50}$ & 10 & 0.0345 & 104.396 & 1.622 & & -0.40 \\
\hline 100 & 10 & 0.00434 & 2190.239 & 1.648 & & 1.21 \\
\hline \multicolumn{7}{|c|}{ Hinged support on the contour } \\
\hline 10 & 10 & 2.8948 & 196.2163 & 1.649 & \multirow{14}{*}{1.579} & 4.27 \\
\hline$\overline{11}$ & 10 & 2.8948 & 196.2163 & 1.649 & & 4.27 \\
\hline 12 & 10 & 2.4837 & 206.7266 & 1.604 & & 1.61 \\
\hline$\overline{13}$ & $\overline{10}$ & 2.1492 & 218.6445 & 1.627 & & 2.98 \\
\hline$\overline{14}$ & 10 & 1.8109 & 231.331 & 1.604 & & 1.61 \\
\hline$\overline{15}$ & $\overline{10}$ & 1.5463 & 245.0727 & 1.604 & & 1.61 \\
\hline$\overline{16}$ & 10 & 1.3233 & 259.5791 & 1.605 & & 1.62 \\
\hline$\overline{17}$ & $\overline{10}$ & 1.1361 & 274.6978 & 1.605 & & 1.61 \\
\hline 18 & 10 & 0.9791 & 290.3586 & 1.605 & & 1.60 \\
\hline$\overline{19}$ & $\overline{10}$ & 0.8474 & 306.4941 & 1.605 & & 1.61 \\
\hline 20 & 10 & 0.7367 & 323.0117 & 1.605 & & 1.62 \\
\hline 30 & 10 & 0.6433 & 339.8903 & 1.605 & & 1.64 \\
\hline 50 & 10 & 0.2068 & $\overline{519.152}$ & 1.605 & & 1.63 \\
\hline 100 & 10 & 0.0459 & 899.3132 & 1.604 & & 1.54 \\
\hline
\end{tabular}

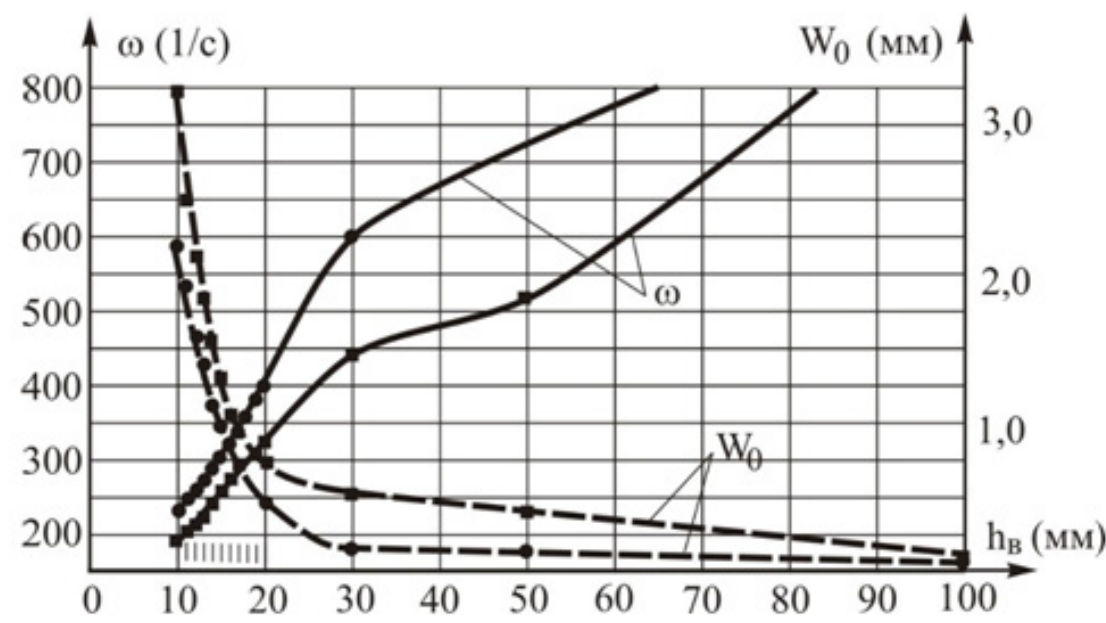

Figure 2 : Graphs of the change of the maximum deflections WO and the frequencies of the natural oscillations $\omega$ of the plates depending on the change in the thickness of one of the layers of the twolayer plate 


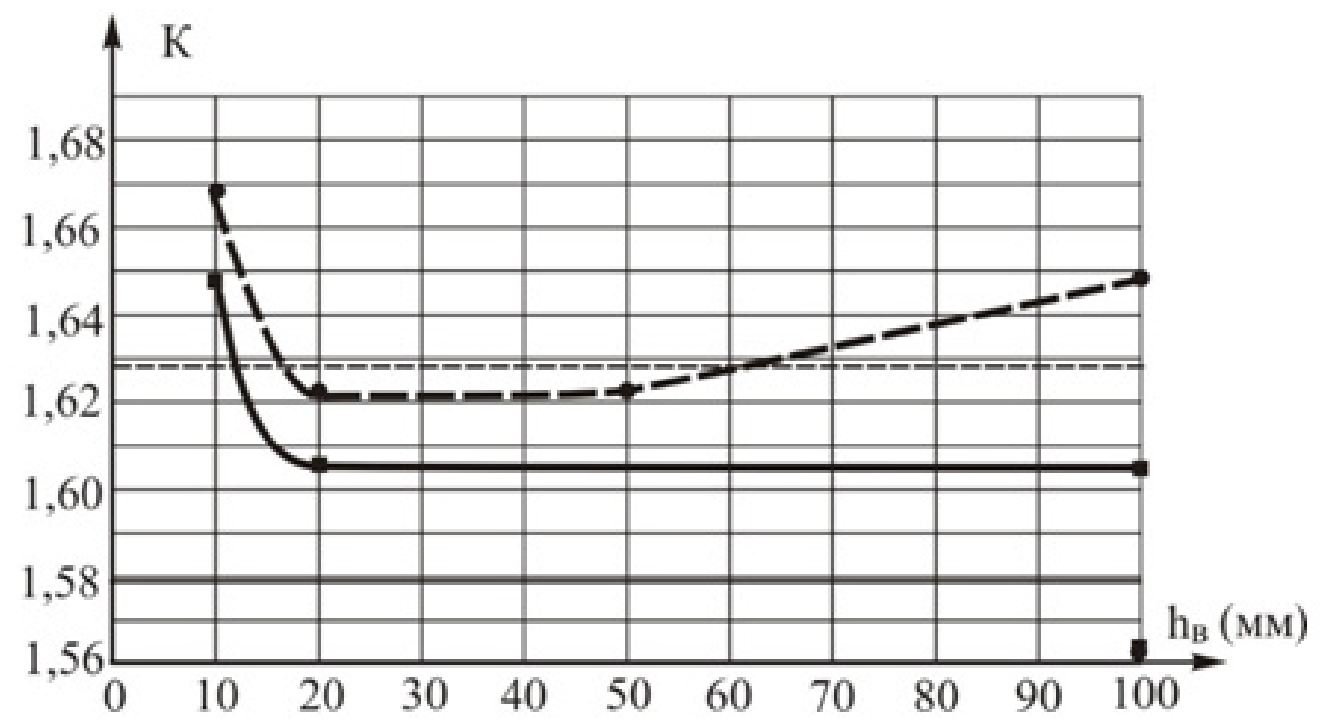

Figure 3: Graphs of the coefficient $K$ change depending on the change in the thickness of one of the layers of a two-layer plate in comparison with its analytical value.

\section{CONCLUSION}

As a result of numerical investigation, we determined that as the thickness of one of the layers of the composite plate increases, the frequency of its free oscillations increases and the deflection decreases, that is, the rigidity of the plate increases. Proportionality coefficients $\mathrm{K}$, which were received in the calculation, differ from analytical values with a discrepancy of not more than $4.3 \%$.

\section{REFERENCES}

1) Rzhanitsyn A. (1986) Sostavnyesterzhn I iplastinki [Composite rods and

2) KorobkoV.I.(1989)Ob odnoj "zamechatel'noj" zakonomernosti $v$ teoriiuprugihplas-tinok [About one "remarkable" regularity in the theory of elastic plates]. The news of higher educa-tion institutions. Construction and architecture. no. 11. pp. 32-36. (in Russian)

3) Korobko V., Korobko A. (2010) Stroitel'nay amekhanikaplastinok: Tekhnicheskayateoriya[Construction mechanics of plates: Technical theory]. M.: publishing house "Spektr", 410 p. (in Russian)

4) Marfin K. (2015) Vzaimosvyaz' maksimal'n yhprogibovisobstvennyhchastotpoperechnyhkolebanijsostavnyhplastinnapodatlivyhsvyazyah [Correlation of the maximum sags and natural frequencies of cross oscillations of composite plates on pliable communica- tions]. Candidate thesis for in Engineering Sciences, Orel, 150 p. (in Russian)

5) Turkov A. (2008) Vzaimosvyaz' zadachdinamiki I statikisploshnyh I sostavnyhderevyan-nyhkonstrukcij [Correlation of tasks of dynamics and statics of continuous and compo-site wooden constructions]. Doctoral thesis in Engineering Sciences, Orel, 386 p. (in Russian)

6) Turkov A., Marfin K. (2011) Progiby I chastity sobstvennyhkolebanijsostavnyhkvadrat-nyhizotropnyhplastin s razlichnymigranichnymiusloviyamipriizmeneniizhestkostisvya-zejsdviga [Deflections and frequencies of natural oscillations of composite square iso-tropic plates with different boundary conditions in case of change of rigidness of shift bindings]. Construction and reconstruction, Orel: FSBEE HPE "State University - UNPC", no. 4, pp. 38-42. (in Russian)

7) Turkov A., Marfin K. (2011) Tochnost' rez ul'tatovchislennyhissledovanijkvadratnyhs os-tavnyhizotropnyhplastinnapodatlivyhsvyazyahprirazlichnomkolich-estvekonechnyhehlementov [The accuracy of results of numerical researches of square composite isotropic plates on pliable bindings in case of different quantity of terminal elements]. Construction and reconstruction, Orel: FSBEE HPE "State University - UNPC", no.6, pp. 43-49. (in Russian)

8) Turkov A., Marfin K. (2013) Issledovaniepro- 
gibovichastotsobstvennyhkolebanijkruglyhtranstropnyhplastin [The study of deflections and frequencies of natural oscillations of round transversely isotropic plates]. News of higher educational institutions. Forest magazine, no. 4, pp. 66-71. (in Russian)

9) Turkov A., Marfin K. (2014) Metodikaprovedeniyaehksperimentadlyastaticheskogoidi-namicheskogoispytaniyaizotropnyhsostavnyhplastinnapodatlivyhsvyazyah [The proce-dure of carrying out an experiment for static and dynamic test of the isotropic composite plates on pliable bindings]. Construction and reconstruction, no. 4, pp. 31-36. (in Rus-sian)

10) Turkov A., Marfin K. (2015) Eksperimental 'nyeissledovaniyasostavnyhkruglyhplastinnadinamicheskie I staticheskienagruzki [The pilot studies of composite circular plates for dynamic and static loads]. Construction and reconstruction, no. 3, pp. 60-66. (in Russian)

11) Turkov A., Karpova E. (2015) Issledova niekoehfficientazhyostkostidlyatreugol' nojsos-tavnojizotropnojplastiny $\mathrm{v}$ zavisimostioteyoosnovnoj chastity kolebanijpriraznojzhyost-kostisvyazejsdviga [The study of a seam stiffness coefficient for a triangular composite isotropic plate depending on its basic frequency of oscillations in case of different rigid-ness of shift bindings]. Construction mechanics and calculation of constructions, no. 2, pp. 66-69. (in Russian)

12) Turkov A., Abashina N., Karpova E. (2016) Progibyi chastity sobstvennyhkolebanijsos-tavnyhrombicheskihizotropnyhplastin, sharnirnoopyortyhpokonturupriizmeneniizhyost-kostisvyazejsdviga [Sags and frequencies of natural oscillations of composite rhombic isotropic plates pivotally supported on a circuit in case of change of rigidness of shift bindings]. Construction and reconstruction, no. 5, pp. 45-50. (in Russian)

13) Kalmanok A. (1950) Stroitel'nayamekhanika plastinok [Construction mechanics of plates]. M.: Mashstroyizdat, 303 p. (in Russian)

14) Semenov A., Gabitov A. (2005) Proektnovychislitel'nyjkompleks SCAD v uchebnomprocesse. Chast' I. Staticheskijraschet [The SCAD project computer system in educational process. Part I. Static calculation]. M.: ASV publishing house, 152 p. (in Russian)
15) Shaposhnikov N. (1968) Raschetplastinoknaizgibpometodukonechnyhelementov [Cal-culation of plates on a bend according to the finite-element method]. Works of MITE, is-sue 250, pp. 134 - 144. (in Russian)

16) Rzhanitsyn A. (1976) Raschetsostavnyhplastinok $s$ absolyutnozhestkimipoperechny-misvyazyami [Calculation of composite plates with absolutely tight cross couplings]. Researches on the theory of constructions, issue XXII, M.: Stroyizdat, pp. 120-133. (in Russian)

Paper sent to revision: 21.07.2017.

Paper ready for publication: 07.09.2017. 